\section{Case Reports in Neurology}

Case Rep Neurol 2020;12:183-188

DOI: 10.1159/000507277

Published online: December 14, 2020
(C) 2020 The Author(s)

Published by S. Karger AG, Basel www.karger.com/crn

This article is licensed under the Creative Commons Attribution-NonCommercial 4.0 International License (CC BY-NC) (http://www.karger.com/Services/OpenAccessLicense). Usage and distribution for commercial purposes requires written permission.

\title{
Nonbacterial Thrombotic Endocarditis Related to Adenocarcinoma of the Uterine Cervix
}

\author{
Naruchorn Kijpaisalratana ${ }^{a, c, d} \quad$ Aurauma Chutinet ${ }^{a, b}$ \\ Suporn Travanichakul, ${ }^{a}$ Teeraparp Kitjawijit ${ }^{a, b}$ Pajaree Yokumporn ${ }^{a}$ \\ Kotchakorn Duangjino ${ }^{a} \quad$ Nijasri C. Suwanwela ${ }^{a, b}$ \\ aDivision of Neurology, Department of Medicine, Faculty of Medicine, Chulalongkorn \\ University, Bangkok, Thailand; ${ }^{b}$ Chulalongkorn Comprehensive Stroke Center, King \\ Chulalongkorn Memorial Hospital, Bangkok, Thailand; 'Chula Neuroscience Center, King \\ Chulalongkorn Memorial Hospital, Bangkok, Thailand; dDivision of Academic Affairs, \\ Faculty of Medicine, Chulalongkorn University, Bangkok, Thailand
}

\section{Keywords}

Nonbacterial thrombotic endocarditis · Marantic endocarditis · Cervical cancer ·

Adenocarcinoma

\begin{abstract}
We report a 66-year-old female patient who presented with acute onset of visual loss with relative afferent pupillary defect, hemineglect, hemihypesthesia, and apraxia. Magnetic resonance imaging of the brain demonstrated different stages of ischemic stroke in different vascular territories, suggesting cardiogenic embolism. Past history was significant for advancedstage adenocarcinoma of the uterine cervix under chemoradiation treatment. On echocardiogram, vegetation at the aortic valve was observed. With the absence of evidence of infectious endocarditis, diagnosis of nonbacterial thrombotic endocarditis was made, and the patient was treated by long-term anticoagulant. This case is unique in terms of the adenocarcinoma cell type of cervical cancer, which is uncommon and has been rarely reported to be related to nonbacterial thrombotic endocarditis.

(C) 2020 The Author(s)

Published by S. Karger AG, Basel
\end{abstract}

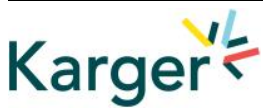

Nijasri C. Suwanwela

Division of Neurology, Department of Medicine, Faculty of Medicine

Chulalongkorn University, 1873 Rama IV Road

Bangkok 10330 (Thailand)

nijasris@yahoo.com 


\section{Case Reports in Neurology}

Case Rep Neurol 2020;12:183-188

DOI: 10.1159/000507277

(c) 2020 The Author(s). Published by S. Karger AG, Basel www.karger.com/crn

Kijpaisalratana et al.: Nonbacterial Thrombotic Endocarditis Related to Adenocarcinoma of the Uterine Cervix

\section{Introduction}

Nonbacterial thrombotic endocarditis (NBTE), previously known as marantic endocarditis, is a well-documented clinical condition related to hypercoagulability state. It has been associated with many inflammatory states including autoimmune diseases and malignancy. We report a case of adenocarcinoma of the uterine cervix associated with NBTE. The cell type of adenocarcinoma is an uncommon presentation of cervical cancer. In addition, ischemic stroke due to NBTE from cervical adenocarcinoma has been rarely reported $[1,2]$.

\section{Case Presentation}

A 66-year-old female presented with abnormal feelings of her left arm and leg $4 \mathrm{~h}$ prior to hospital arrival. Her daughter stated that after the patient woke up, she kept on asking "Where is my left arm and leg?" Three days earlier, she had 2 episodes of transient binocular visual loss lasting for $5 \mathrm{~min}$, which was completely recovered in her left eye. However, her right eye vision remained impaired. She was diagnosed to have stage IIB poorly differentiated adenocarcinoma of the cervix, which was diagnosed 1 year ago and currently treated by carboplatin and radiation. In addition, she also had had hypertension and type 2 diabetes mellitus for 30 years. On physical examination, she was afebrile. Her vital signs were stable with a blood pressure of 140/76 mm Hg and a pulse rate of $76 \mathrm{bpm}$. She had grade II systolic ejection murmur at the left lower parasternal border. Visual acuity test demonstrated finger count in her right eye and 20/70-1 in her left eye. Fundoscopic examination revealed pale optic disc in her right eye. Her pupils were $3 \mathrm{~mm}$, reactive to light bilaterally with relative afferent pupillary defect of the right eye. She had normal motor power in all extremities. Mild clumsiness of her left hand and mild ataxia of the left arm and leg were observed. She had decreased pinprick sensation on the left side of her face and left hemibody. Her proprioception was impaired in the left hand and foot. She also had left-sided tactile neglect and ideomotor apraxia.

Magnetic resonance imaging of the brain demonstrated acute to subacute infarction in many brain regions including the right parietal lobe, right temporo-occipital lobe, right supramarginal gyrus, right anterior frontal lobe, and medial left occipital lobe (Fig. 1). CT angiography revealed abrupt occlusion of the right distal branch of the middle cerebral artery without significant luminal stenosis of other intracranial and extracranial arteries (Fig. 2a). She was admitted to the stroke unit. Initially, aspirin was prescribed for secondary stroke prevention. The cardiac source of emboli was thoroughly investigated due to the pattern of infarction from magnetic resonance imaging. Atrial fibrillation was not detected on 12-lead electrocardiogram and Holter monitoring. Transesophageal echocardiography demonstrated a thickened trileaflet aortic valve with multiple small oscillating masses at all leaflets (Fig. 2b). She was afebrile during admission and her blood culture was negative. Her D-dimer was elevated with a level of $9,182.72 \mathrm{ng} / \mathrm{mL}(<500 \mathrm{ng} / \mathrm{mL})$. Other blood tests for hypercoagulable state were unremarkable. NBTE was diagnosed. Anticoagulant therapy was initiated by lowmolecular-weight heparin. Prior to hospital discharge, her tactile neglect and ideomotor apraxia improved. During the follow-up period, further investigation was performed by FDGPET scan and revealed multiple pulmonary metastasis. Unfortunately, 2 months after ischemic stroke, the patient developed dyspnea and died from respiratory failure.

\section{Karger'=}




\section{Case Reports in Neurology}

Case Rep Neurol 2020;12:183-188

DOI: 10.1159/000507277

(c) 2020 The Author(s). Published by S. Karger AG, Basel www.karger.com/crn

Kijpaisalratana et al.: Nonbacterial Thrombotic Endocarditis Related to Adenocarcinoma of the Uterine Cervix

\section{Discussion}

NBTE is characterized by noninfective vegetation of cardiac valve. NBTE vegetation results from deposition of thrombi composed of platelets and sterile fibrin that lack of bacteria or inflammation on the heart valves. The vegetations are generally superficial with entirely normal valvular tissue or only subtle histologic changes on the surface. The absence of cellular organization makes the vegetations friable and, therefore, easy to dislodge and has a high tendency to embolize [3]. The most common sites of vegetation are the mitral and aortic valves. Symptoms usually occur due to embolization of thrombi into the brain and other organs. Although the entire mechanisms of NBTE development is still unclear, elevated levels of cytokines such as tumor necrosis factor and interleukin- 1 are shown to be related to local tissue damage and activation of coagulation cascade [4].

NBTE is often found during autopsy or at the late stage of malignancies. However, NBTE should be suspected in patients with recurrent embolism and ischemic stroke with variable size of infarction in multiple territories, with or without known malignancies. When there is a high index of suspicion of NBTE, transthoracic followed by transesophageal echocardiography should be performed to search for vegetations. The premortem diagnosis of NBTE is usually made based on clinical and echocardiographic findings together with the exclusion of an infectious cause of endocarditis [5].

The most common histologic type of malignancy related to NBTE is adenocarcinoma. Lung, pancreas, stomach, and adenocarcinomas of unknown primary site are the most common types of malignancy [4]. For gynecologic malignancies, ovarian cancer is the most common cancer related to NBTE [6]. The case of stroke secondary to NBTE in a patient with cervical cancer has been rarely reported $[1,2]$. The cell type in this patient was adenocarcinoma, which is an uncommon cell type found in less than $20 \%$ of the cervical cancer patients. This cell type tends to be more aggressive and has a smaller survival rate than the squamous cell type [7].

For the management of NBTE, treatment of the underlying disease as well as managing the risk for systemic embolization are key. Anticoagulation is necessary for preventing recurrent embolization [8]. Long-term anticoagulation with full-dose intravenous heparin or lowmolecular-weight heparin is recommended by the American College of Chest Physician guidelines [9]. Many studies have shown that heparin therapy can decrease the thromboembolic complications including stroke, especially in patients with malignancy. In contrast, the efficacy of warfarin treatment is still unclear. Additional research is required to study the effects of non-vitamin K antagonist on NBTE. Other treatments include valvular repair or replacement, which is only indicated in patients with severe valvular dysfunction, large vegetations, or recurrent embolism despite long-term anticoagulation therapy. The evidence of steroid treatment is still inconclusive. However, it should be used in NBTE-related autoimmune disease. The prognosis of cancer-related NBTE is generally poor due to the multiple and recurrent nature of stroke and the advancement of malignancy.

\section{Statement of Ethics}

Informed consent was obtained from the patient's relative for the publication of this report.

\section{Karger'=}




\section{Case Reports in Neurology}

\section{Conflict of Interest Statement}

None of the authors have conflicts of interest to disclose.

\section{Funding Sources}

There was no funding source for this case report.

\section{Author Contributions}

N.K. and N.C.S. developed the main concept and wrote the manuscript. S.T., T.K., P.Y., and K.D. collected patient information. A.C. and N.C.S. reviewed and edited the manuscript. All authors read and approved the final manuscript.

\section{References}

1 Hottois E, Weichselbaum L, Guérisse F, Doriath V. [Neurologic disorder complicating a cervical cancer]. Rev Med Brux. 2014 Mar-Apr;35(2):72-7.

2 Glass JP. The diagnosis and treatment of stroke in a patient with cancer: nonbacterial thrombotic endocarditis (NBTE): a case report and review. Clin Neurol Neurosurg. 1993 Dec;95(4):315-8.

3 Aryana A, Esterbrooks DJ, Morris PC. Nonbacterial thrombotic endocarditis with recurrent embolic events as manifestation of ovarian neoplasm. J Gen Intern Med. 2006 Dec;21(12):C12-5.

4 el-Shami K, Griffiths E, Streiff M. Nonbacterial thrombotic endocarditis in cancer patients: pathogenesis, diagnosis, and treatment. Oncologist. 2007 May;12(5):518-23.

5 Joshi SB, Richards MJ, Holt DQ, Yan BP, Aggarwal A. Marantic endocarditis presenting as recurrent arterial embolisation. Int J Cardiol. 2009 Feb;132(1):e14-6.

6 Delgado G, Smith JP. Gynecological malignancy associated with nonbacterial thrombotic endocarditis (NBTE). Gynecol Oncol. 1975 Sep;3(3):205-9.

7 Glaze S, Duan Q, Sar A, Lee S, Köbel M, Park E, et al. FIGO Stage Is the Strongest Prognostic Factor in Adenocarcinoma of the Uterine Cervix. J Obstet Gynaecol Can. 2019 Sep;41(9):1318-24.

8 Rogers LR, Cho ES, Kempin S, Posner JB. Cerebral infarction from non-bacterial thrombotic endocarditis. Clinical and pathological study including the effects of anticoagulation. Am J Med. 1987 Oct;83(4):746-56.

9 Whitlock RP, Sun JC, Fremes SE, Rubens FD, Teoh KH. Antithrombotic and thrombolytic therapy for valvular disease: Antithrombotic Therapy and Prevention of Thrombosis, 9th ed: American College of Chest Physicians Evidence-Based Clinical Practice Guidelines. Chest. 2012 Feb;141(2 Suppl):e576S-e600S. 


\section{Case Reports in Neurology}
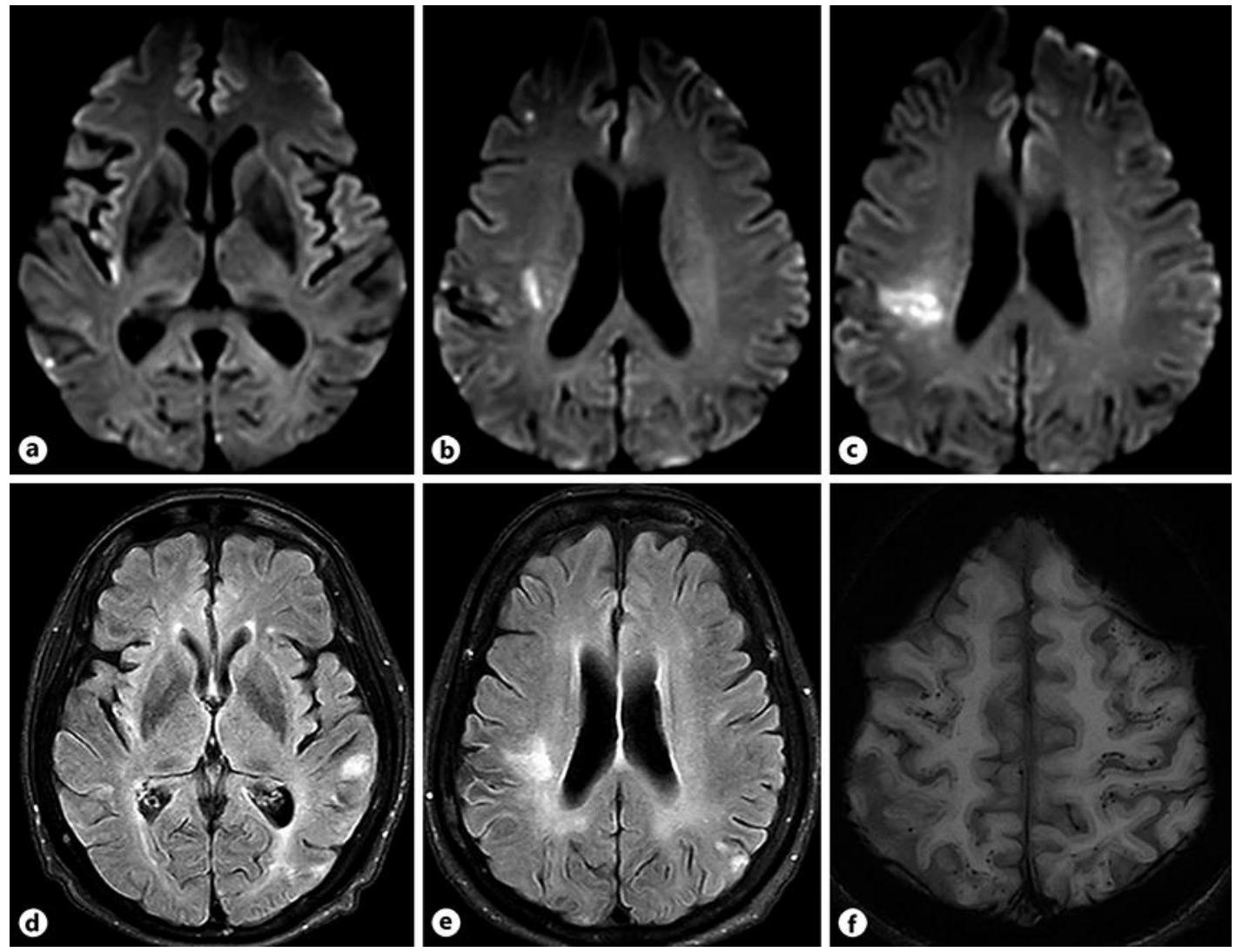

Fig. 1. a-c Diffusion-weighted imaging revealed mild restrict diffusion at the right parietal lobe gyri, deep right corona radiata. d, e Fluid-attenuated inversion recovery revealed multiple subacute cortical-subcortical infarction at the left parietal, left occipital lobe. f Susceptibility-weighted imaging revealed numerous tiny microbleeds along the cortical and subcortical bilateral cerebral hemisphere. 


\section{Case Reports in Neurology}

\begin{tabular}{l|l}
\hline Case Rep Neurol 2020;12:183-188 \\
\hline DOI: 10.1159/000507277 & $\begin{array}{l}\text { @ 2020 The Author(s). Published by S. Karger AG, Basel } \\
\text { www.karger.com/crn }\end{array}$ \\
\hline
\end{tabular}

Kijpaisalratana et al.: Nonbacterial Thrombotic Endocarditis Related to Adenocarcinoma of the Uterine Cervix
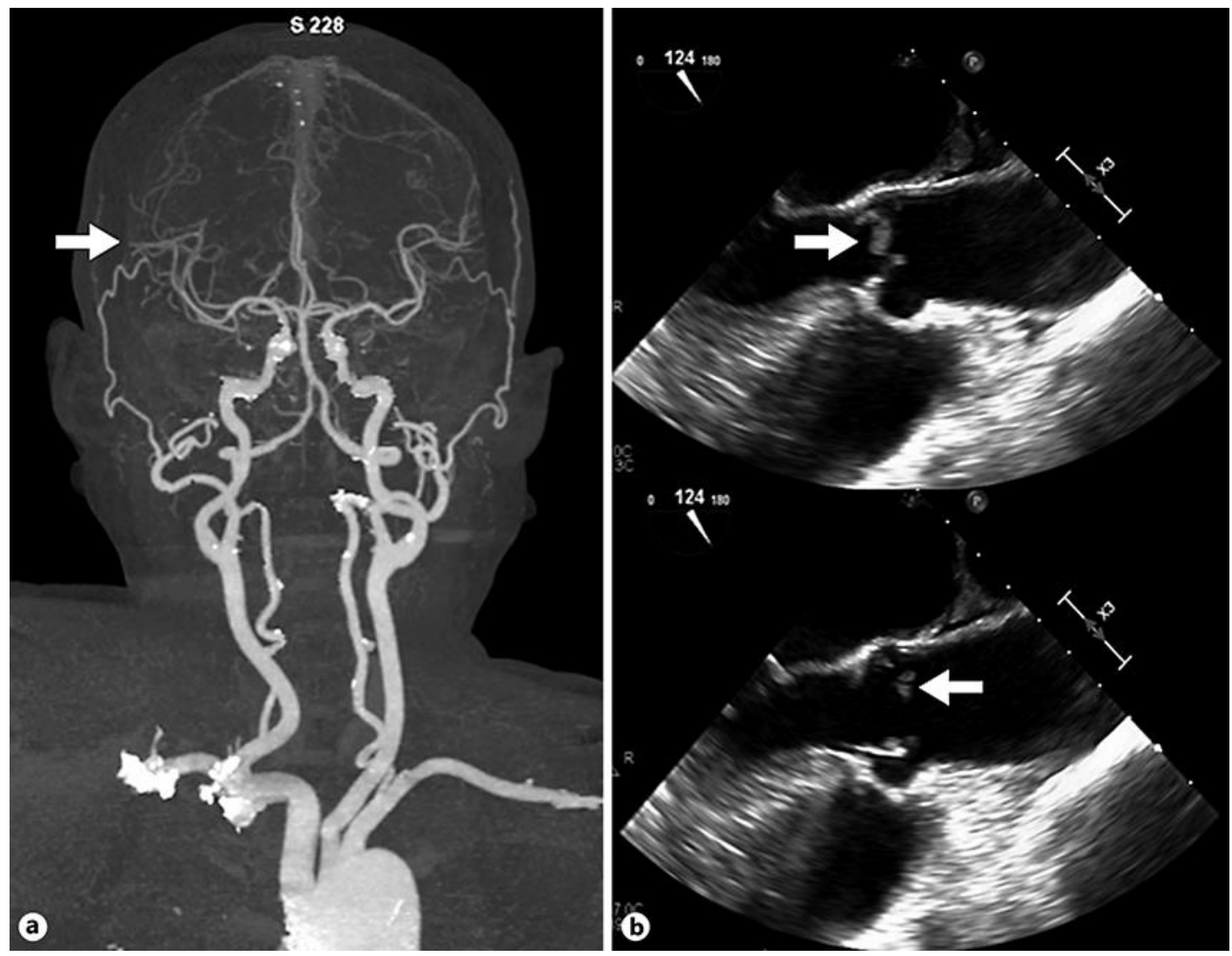

Fig. 2. a Computed tomography angiography of the brain and neck revealed abrupt occlusion of the right distal middle cerebral artery with a relatively diminished cortical branch of the right middle cerebral artery territory. $\mathbf{b}$ Transesophageal echocardiography demonstrated thickened trileaflet aortic valves with multiple small oscillating masses at all leaflets with malcoaptation of the aortic valves. 